\title{
TELL and CALL for ALL: Successful Strategy Use in Second Language Learning
}

\author{
By John Paul Loucky, Seinan JoGakuin University, Kitakyushu, JAPAN \\ (loucky@seinan-jo.ac.jp or via Contact Page of www.CALL4ALL.us Homepage)
}

\begin{abstract}
This article reviews studies on ways to help maximize vocabulary and reading development online. Needs of limited English proficiency learners, especially those from East Asia are addressed, with many recommendations given of ESL/ EFL Gold programs with greatest potential to help increase motivation and spur more rapid L2 acquisition. The pedagogical goal was to find multi-level, integrated technology-enhanced (TELL) or computer-assisted language learning (CALL) programs that serve to increase language learners' (LLs) use of glossing and interactive programs to help them rapidly build up their target language (TL) vocabulary and reading skills.
\end{abstract}

Keywords: language strategies training, Vocabulary Learning Strategies (VLSs); vocabulary and reading levels; testing proficiency; portable and online dictionaries; Second Language Vocabulary Acquisition (SLVA); ELLs: English Language Learners

\section{Introduction}

Because of the proliferation of languagelearning programs and websites, it becomes important to help define which most essential vocabulary and reading strategies should be included. When designing programs and websites, the three major parameters of subjective enjoyment, objective effectiveness, and technological efficiency should all be considered. This article compares various studies to suggest how many features and functions of CALL tools can be used at the most appropriate stages of lexical processing and acquisition to make vocabulary learning smoother, quicker, and more effective. The vocabulary learning strategies taxonomy presented here seeks to integrate research studies to create a user-friendly systemfor more rapid vocabulary acquisition/activation.

Neil Anders on (1991) originally looked at "Individual differences in strategy use in second language reading and testing," and later provided a succinct definition and clear focus statement on L2 learning strategies, in which strategies are defined as "conscious actions that learners take to improve their language learning" (Anderson, 2005, p. 757), whether these are outwardly observable or merely mental. (p. 757) He further states that strategies should be viewed not as single actions, but more often as a repertoire of skills, and uses the analogy of beautiful music resulting from the process of wellorchestrating instruments together.

He describes strategy use as follows: "Because strategies are conscious, there is active involvement of the L2 learner in their selection and use. Strategies are not is olated actions, but rather a process of orchestrating more than one action to accomplish an L2 task." (p. 757) This being the case, language strategy training needs to raise learners' awareness and ability to assess a range of L2 vocabulary learning and comprehension strategies to help them become more proficient in their orchestrated use (for one simple 
systemfor doing so see Loucky, 2005b, JALT 2004].)

\section{Literature Review}

Anderson (2005) examined research about various L2 learning strategies favored by current language teaching methodologies in order to consider both present directions to better "anticipate the future of L2 strategy research" (p. 757). The most extensive language learning strategies bibliography then was at http://linguistics.byu.edu/faculty/andersonn/le arningstrategies/LearningStrategies.pdf. Teacher Technology Guides are greatly needed as those found at Edudemic's www.http//edudemic.com/2013/05/theteachers-guide-to-choosing-the-best-digitalcontent and ours/Kapuler's at

www.CALL4ALL.us.

\section{L2 Strategies Research Questions and Developments}

This study investigated how online reading comprehension and vocabulary learning strategies training could be most effectively combined with training in the use of particular online functions to enhance Chinese and Japanese students' learning of English online. They were engaged in a "Collaborative Writing Exchange Project" using similar online vocabulary development tools. All target terms were pre-organized and made available under common Semantic Field Keywords online in both Japanese and Chinese, but students had freedom to choose within sets of most relevant words, from five academic disciplines. Writing themes were suggested to learners in both countries, to keep their email exchanges consistent.

Eight most essential vocabulary learning steps, skills and strategies were isolated and analyzed, based on a review of literature in the fields of L1 and L2 lexical acquisition and vocabulary development, as well as on studies done by the author at seven colleges in Kyushu, Japan (Author, 2006). Teaching language learners how to systematically apply this series of crucial strategies can be one of the most effective ways to help them to maximize their vocabulary and language development. This cyclical "Taxonomy of Foreign Language Vocabulary Learning Strategies" was advanced and explained by this writer, showing eight cognitive vocabulary learning processes found to be most effective in his testing, teaching and analys is of Japanese college students' study of English as a foreign language. Also ways of "Systematically maximizing vocabulary development by using a depth of lexical processing scale and vocabulary learning strategies taxonomy" were also proposed and demonstrated in otherstudies (Author, 2005), noting Schmitt`s (1997) model.

The authorbegan "Developing and testing vocabulary training methods and materials for Japanese college students studying English as a foreign language," his dissertation topic in the 1990s (Loucky, 1996), going on to as sess the potential of semantic fields and computerized electronic dictionaries for maximizing English vocabulary learning (Loucky, 2004, 2010). He went on to compare the learning of East Asian character-based languages with Greco-Roman-based English vocabulary (Loucky, 2005a), and recommended "Combining beneficial strategies from both intensive and extensive reading approaches for more effective and enjoyable language learning (Loucky 2005b).

A review of the past thirty years of research on learning strategies by Cohen \& Macaro (2007) has been done recently. It provides a useful re-examination of key is sues such as strategies in context, strategy instruction, and strategy research methods by numerous experts in the field. It proposes a clear and focused research agenda, questioning formerly popular learning strategies models in vogue in the 1990s. Representing new trends and challenges to the older Oxford (1990) SILL Frame-work 
while explaining the need for more careful definitions is research review by Rose (2012), who questions older models, stating learner strategy training should be more informed by recent developments in selfregulation and self-access studies. To help encourage teachers, EducatorU can help with educational technology planning and mentoring with Teacher Appreciation videos: [http://www.edutopia.org/blog/filmfestival-teacher-appreciation].

\section{Questions for CALL Research}

This review proposes using Chapelle \& Jamieson's (2008) text's principles to compare print-based with computerenhanced learning in each of the seven major areas of language learning. Teaching methodologies for L2 language learning have been studied extensively since the 1970s. Early studies consistently addressed 5 particular strategies, referenced by Anders on (2005) including: "1) memorization strategies,2) clarification strategies, 3)communication strategies, 4) monitoring strategies, and 5) prior knowledge strategies" (p. 758)

Since everyone does not learn in the same way, both David Nunan (1991) and Rebecca Oxford (1990) emphasized that one size would not necessarily fit all, although good strategies training should reason-ably result in more effective language learning. We surveyed reading and vocabulary learning strategies used by Japanese graduate students, with research on online dictionaries

\section{METHOD}

\section{Research Questions:}

Questions examined in previous studies by the author have focused on and included: "How can one betteruse modern CALL resources to help language learners to build up a larger TL (target language vocabulary quickly?"

\section{STUDY PROCEDURES}

As in the previous pilot study with same level of Japanese graduate Engineering Master's students, this study also sought to assess their incoming and outgoing vocabulary levels and strategies learned in just one fall semester course in Practical Integrated English, using mostly an online reading and writing approach. A 40-item survey of students 'vocabulary learning strategies (VLSs) was used, based on a VLS Taxonomy developed and tested previously, accessible online from the V-Page of the class site www.CALL4ALL.us. In addition, a brief survey of users ` perceptions of online dictionaries was given, using questions. asked by Jin \& Deifell (Forthcoming).

A five-part system including major factors of Language Learning Task, Type of Target Word, Need, Search and Evaluation_can help both students and teachers better monitor their vocabulary learning in L1 or L2. This systemis used to keep learners on task and help them process new words at deeper, multiple levels. Students can write in evidence of HOW they processed these new words, or print out CMS from WordChamp.com to prove it. (Tasks are based on modification of Laufer \& Hulstijn, 2001) Teachers mark +/- for degree of Need, Search and Evaluation involved in each learning task. Students ideally should be taught how to monitor which of these 8 lexical processing phases they are using, while telling HOW they used each strategy shown.

\section{RESULTS:}

Participants: Tested and surveyed students consisted of 6 Chinese and 40 Japanese graduate Engineering students in their first year of an engineering Master's program, plus 1 second year student $(\mathrm{N}=47)$. Both objective and 
subjective assessments were made of their learning. Pre-and Post-test of their vocabulary levels were given using standardized Gates-MacGinite test Forms C \& F. Their average vocabulary level was checked at the start of this onesemester fall course and found to be as follows, shown in Tables $1 \& 3$. VChecks and SFKA Study and Quiz were given each year, but Balsamo Reading Lab was used only two out of three years (2005 \& 2006). In Table 3 Japanese Engineering Graduate student responses to an 18 -item survey-replicated from Jin $\&$ Deifell--are summarized. Survey of their "Online Dictionary and Reading Strategies" was also given (Powerpoint).

\section{Previous Strategy Research}

In 2006 Author proposed that we might best help language learners to maximize their vocabulary development by systematically using a depth of lexical processing taxonomy, CALL resources, and effective strategies in a wellintegrated way. In that proposal he offered an 8-phase systemto help both students and teachers better monitor vocabulary learning in L1 or L2. This systemmay also be used to help keep learners on task, urging them to process new words at deeper, multiple levels. Students can write in evidence of HOW they processed these new words, or print out data based on a Course/Content Management System (CMS) such as that from WordChamp.com to show what they are actually doing with new words they encounter. Students ideally should be taught how to monitor which of these 8 lexical processing phases they are using by circling and telling or showing how they used each strategy listed.

The writer's previous 2005-2006 distance learning project involved five writing exchanges between Chinese and Japanese students of English. It made use of Semantic Field Keyword program with Chinese and Japanese support [http://www.call4all.us///misc/sfka.php], as well as insights about monitoring learner's vocabulary learning system from Hulstijn \& Laufer (2001), as well as Chinese Students' vocabulary learning strategy categories (based on $\mathrm{Gu}$ and Johnson's 1996 Hong Kong Study of 850 non-English majors in Beijing's use of 108 VLSs). Clearly this writer's belief is most in line with survey choice c) "Words should be studied and put to use, known as an Intentional or Intensive Approach" regarding beliefs about vocabulary learning.

\section{Vocabulary 'Threshold Levels Exist}

The author demonstrated the existence of a common 'Threshold Level' of essential kanji and English vocabulary in a review of "East Meets Western Language Systems" (Loucky, 2005a). It is well known that less proficient FL/SL readers usually fall below what has become known as the minimum 'threshold' neces sary for independent reading.

The above studies classified VLSs using a "Depth of Lexical Processing Scale" and "Taxonomy of Vocabulary Learning Strategies.". Both show established principles and strategies used in effective vocabulary learning, which should be taught and practiced as regularly as possible to help language learners develop their semantic knowledge and fluency more rapidly. It describes most essential vocabulary learning strategies based on extensive comparison of many research studies in L2 vocabulary acquisition, as well as original studies done in Japan with Japanese, Chinese and Korean students. While many of these students did not regularly use these processing steps sy stematically, most recognized the value of doing so after being introduced to them. In addition, this eight-fold system can be taught bilingually in a way that is clear, simple and memorable. One can also draw a culturally sensitive and appropriate parallel with Buddhism's eight-fold path of right belief, emotions, actions, effort, words, awareness, concentration, and ways of living. 
While focused and intentional, explicit teaching with deliberate learning goals set is most important at initial stages of learning a new language, such direct teaching of most high frequency vocabulary also needs to be balanced with substantialopportunities for incidental learning through both wide chances for extensive reading and listening as well as opportunities given for language USE in oral and written elaboration activities.

\section{Investigating Successful Vocabulary}

Various glossing programs were recently tested by the writer with a co-researcher in Tokyo to help learners improve their online reading and vocabulary learning skills (See Loucky \& Tuzi, 2010), overviewed in an online Slideshow http://www.wiziq.com/tutorial/30502Successful-Vocabulary-Learning-Online . This study sought to use a similar method to investigate the levels of Japanese engineering students and which online dictionaries and online strategies they used while reading and writing online. As shown there 2 of 3 programs improved learners' vocabulary using internal glosses by one with external did not.

\section{Discussion}

In the earlier pilot study (Loucky, 2006), most Japanese college students tested showed a low average use of VLSs, except for students in the most advanced class. Despite having had an average of 7.32 years of previous study in English, only about half of the students $(52 \%)$ reported using even the first three of the eight stages of vocabulary learning. Although three fourths of the students (74\%) thought that each of the eight types of VLSs would be useful for language learning, their average use of all eight steps was only $37 \%$.
Students in the lower proficiency level classes used, on average, only $26 \%$ of the 40 VLSs. The most widely used strategies were accessing unknown words in Japanese (62\%, compared to only $20 \%$ for accessing unknown words in English), asking classmates for help or using an English-Japanese book dictionary (50\%), archiving/recording meanings of unknown words or simply skipping over unknown words (45\%), trying to guess meanings from context (40\%), using monolingual dictionaries (37\%), and using English to Japanese electronic dictionaries (35\%, compared with $25 \%$ for using Japanese to English electronic dictionaries). The other VLSs were used by under $30 \%$ of the lower proficiency level students.

The graduate students tested used a slightly higher percentage of VLSs than the lower proficiency undergraduate students, $32 \%$ versus $26 \%$. However, the most proficient undergraduate students (Group 3), who had the highest average use of electronic dictionaries, also had the highest average use of VLSs (41\%). This group also had an average vocabulary gain of 1.07 grade over the acade mic year, the second highest vocabulary gain observed by the researcher in the past decade at this institution. Students who used electronic dictionaries consistently and diligently generally reached higher levels of English proficiency than those who did not (Loucky, 2010).

Graduate students in the current study (Group 6) were compared with this previous most similar class (Group 5), using the same taxonomy of VLS assessment instrument. After more inclass instruction about their use, such strategy instruction helped learners use them more frequently as their awareness of their importance increased. A later study examined which sites they made 
most use of to improve their online learning, which enabled them to increase their English vocabulary level by an average of $2+$ grade levels, the best growth seen at this college, in Table 1.

Table 1: Integrated English Graduate Japanese Engineering Students' Gains

\begin{tabular}{|l|l|l|l|}
\hline $\begin{array}{l}\text { 10/2012 Gates } \\
\text { C Level }\end{array}$ & $\begin{array}{l}\text { SFK } \\
\text { A \% }\end{array}$ & $\begin{array}{l}\text { Quiz } \\
\text { Ave. 1-1 }\end{array}$ & $\begin{array}{l}\text { V-Check } \\
\text { Level }\end{array}$ \\
\hline Grade & \multicolumn{1}{|c|}{$\%$} & & \\
\hline 3.93 & 71 & 33.95 & $3,556.9$ \\
\hline
\end{tabular}

\begin{tabular}{|r|r|r|}
\hline $\begin{array}{l}\text { Estimated TO EC } \\
\text { Conversion }\end{array}$ & $\begin{array}{l}\text { 2/2013 Gates F } \\
\text { Voc-Le vel }\end{array}$ & $\begin{array}{l}\text { Improve } \\
\text { d Rate }\end{array}$ \\
\hline 442.5 & 6.1 & 2.04 \\
\hline
\end{tabular}

Table 2: Improvement Rates Shown Integrated English Course in Japan

\begin{tabular}{|c|c|c|c|}
\hline $\begin{array}{c}\text { 10/2012 } \\
\text { Gates C } \\
\text { Level }\end{array}$ & $\begin{array}{c}\text { SFK } \\
\text { A \% }\end{array}$ & Quiz Ave. 1-1 & $\begin{array}{c}\text { V- } \\
\text { Check } \\
\text { Level }\end{array}$ \\
\hline $\begin{array}{c}\text { Grade } \\
3.93\end{array}$ & $71 \%$ & 33.95 & $\begin{array}{c}\mathbf{3 5 5 6 . 9} \\
\mathbf{2}\end{array}$ \\
\hline 2/2013 Gates & & $\begin{array}{c}\text { Estimated } \\
\text { TO EIC } \\
\text { Conversion }\end{array}$ & $\begin{array}{l}\text { G } \\
\text { a } \\
\text { i } \\
\text { F Voc-Level }\end{array}$ \\
\hline & & & 2 \\
6.1 & & 442.5 & 0 \\
& & & 4 \\
\hline
\end{tabular}

On a survey students were asked to "Circle each strategy that you regularly use, telling which way of learning new words you find most helpful and enjoyable when using that strategy for learning new words or phrases." Results are shown here in Table 3.

Table 3: 40-Item VLS Taxonomy, Organized by Phases of Lexical Processing
VLS.Score $=$

Level: Reading Grade

I. Initial Discovery or Learning S trategies

\begin{tabular}{|l|l|}
\hline $\begin{array}{l}\text { 1) Attend to New Words } \\
\text { \& Assess them } \\
\text { Use: } 19 \text { Useful: } 10\end{array}$ & $\begin{array}{l}\text { 2) Accessing- } \\
\text { Use: } 12 \text { Useful:19 }\end{array}$ \\
\hline $\begin{array}{l}\text { 3) Archiving- } \\
\text { Use: } 11 \text { Useful: } 16\end{array}$ & 4) Analyzing- \\
\hline
\end{tabular}

\section{Studying and Remembering "Consolidating S trategies"}

\begin{tabular}{|l|l|}
\hline $\begin{array}{l}\text { 5) Associating- } \\
\text { by Semantic Field } \\
\text { Key word approach, } \\
\text { Categorized by } \\
\text { related classes by } \\
\text { such Key words }\end{array}$ & $\begin{array}{l}\text { 6) Anchoring- } \\
\text { in one's memory } \\
\text { (ST) until fixed in LT } \\
\text { Memory. Use } \\
\text { Mnemonics. }\end{array}$ \\
Use: 5 Useful: 17 & Use: 10 Useful: 15 \\
\hline $\begin{array}{l}\text { 7) Activating- } \\
\text { USE- FOCUSED }\end{array}$ & $\begin{array}{l}\text { 8) Reassessing, } \\
\text { Reviewing \& Re- } \\
\text { cycling Exercises: } \\
\text { Use: 14 Useful: 13 }\end{array}$ \\
Use: 11 Useful: 15
\end{tabular}

\section{Results to Date}

This writer`s JALT Vocabulary SIG Poster Sessions have provided an overall menu of language- learning and teaching websites, to help both students and teachers select more useful CALL sites and programs, showing how to combine them into an effective online reading and vocabulary learning program for either classroom- or self-access. This systematic approach can help both kinds of users to better filter through the rivers of online data to find and focus on what we refer to as the 'CALL or ESL/EFL gold,' meaning websites most content-and media-rich for English as a Second/Foreign Language teaching or learning. His VERB SIG postersessions have suggested how to construct an integrated CALL program, including many well-designed sites that combine 
the advantages of using authentic materials with E-tools to simplify them and provide various kinds of vocabulary assessment tools (e.g. original ones at http://call4all.us///home/ all.php?fi=../mi sc/forms ) and language learning support that can aid both students and teachers.

Vance Stevens (2009) was an ESL teacher for 20 years and has since moved through CALL coordination and commercial ESL software development to consultancy in CALL environments and until recently as lecturer in computing at Petroleum Institute, Abu Dhabi. As coordinator of Webheads, he promoted professional development and learner autonomy via social media and collaboration in online spaces. He coined that term "SMALL" during the 25th anniversary of CALL-IS at the TESOL conference in Denver (see slide 8 here: http://www.slideshare.net/vances/ce lebrating-25-years-of-call).

Language teachers using computers need to understand both language and vocabulary acquisition better, as well as software and online programs' wide array of functions and great potential to better advise students, parents and product designers regarding their most effective pedagogical design and use.

The author integrated Grabe`s (2004) principles from L2 reading research with CALL to enhance online vocabulary and reading comprehension. In a similar way 14 CALL principles collated by Hirs chel (2012) will be integrated with Chapelle \& Jamieson`s (2001) previous guidelines and Tips (2008) for operationalizing CALL in the classroom. Chapelle \& Jamieson (2004) recommend that teachers should focus on what students actually do in learning situations (p. 411), to betterclarify students' actual learning processes. To better examine what students actually do in online word- learning situations, this study incorporated observations of students'use of four types of glossing when they read similar texts online.

Because reading online is fast becoming one of the major sources of input for language learners worldwide, the need for teachers to learn how to effectively train students to learn language, specifically vocabulary and reading skills online is becoming increasingly more vital. Clearly teachers need to teach language learners how to deal with the new realities and demands of online reading by helping them learn how to use various supportive computerized language learning functions and strategies more effectively.

\section{Pedagogical Implications}

To better help less proficient English language learners achieve more success in their language learning, the above principles need to be kept in mind and integrated into our teaching materials and curricula. As Loucky (2006) summarized from previous research on CALL,

Chapelle (2001), who outlined the foundations for electronically enhanced teaching, testing and research, noted six major criteria to consider in determining whether a CALL task is appropriate for a given language-learning situation: 1) language learning potential, 2) learner fit, 3) meaning focus, 4) authenticity, 5) impact, and 6) practicality. (p. 365)

When language learning potential is examined, the relevant SLA principle, according to Jamies on and Chapelle (2004) is that an effective language learning activity provides enough chances for a beneficial focus on form. For effective vocabulary development this should include activities that provide enough chances to focus on the form, meaning, and use of the new word 
(Nation, 2001). Thus to be more effective for a wider range of readers, online materials should provide chances for (a) enhanced input, (b) enhanced interaction, and (c) enhanced output/ production. Jamieson and Chapelle provided useful charts to show how to operationalize these variables and identify the factors that should be considered as evidence when seeking to enhance these three aspects of a CALL program's languagelearning potential.

Shield and Kukulska-Hume (2004) have urged that language-learning web sites be designed with usability in mind at all times. Usable systems are those that are easy to learn, "effective to use, and enjoyable or engaging from the user's pers pective" (p. 27). Thus, the three parameters of (a) effectiveness, (b) efficiency, and (c) enjoyment for learners should be kept in constant view when developing CALL programs. (Loucky, 2006). Likewise 5 major kinds of "Potential benefits of CALL instruction" from Hirschel (2012) can serve as clear guidelines of research-supported ways that CALLTELL or SMALL (Social Media-Assisted Language Learning) can be used to enhance language or content learning by building on these inherent strengths of E-Learning tools.

When using Chapelle's parameters and Tips for Teaching with CALL, some of the 14 potential benefits of CALL instruction collated from research by Hirschel (2012) overlap and are useful reinforcements of major principles to keep in mind when using CALL. Although many have noted that use of interesting programs often helps to motivate learners allowing them to engage in more authentic, frequent and meaningful communication, learner empowerment, and effective learning, which social networks are most usefulfor doing so for language learning in particular needs to be further researched. Other motivating programs such as FreeRice.org seem to stimulate learners' desire to get involved in helping raise funds for the poor, etc. CALL promotes learner autonomy by giving them more flexibility to work independently, greater control over learning areas they choose to explore in more depth, with more freedom to work at their own pace. All of these qualities of CALL educational media serve to increase learnercenteredness instead of continuing traditional teacher-centered learning.

In addition to all of these organizational and motivational benefits provided by greater use of CALL, there are particular strengths that technology may provide for language learning since it can help students to better notice and repeat target words and concepts. Four such benefits include more personalized frequent error correction and instant access to word meanings, collocational or concordancing information, all of which are known to be helpful in promoting vocabulary and language acquisition. Multiple encounters and attempts can be given, highlighting important points by making them more salient on screens or adding AV supports for better negotiation and confirmation of new L2 meanings, forms and usage.

Finally several interactional benefits include better equalization of class participation, raising self-confidence levels, and broadening both range and quantity of L2 interactions, by giving them more chances to participate and respond in various multimedia settings. Better yet, when online class interactions are blended, more effective integration of learning seems to take place.

\section{Conclusions}


Many online programs can be used collaboratively to improve learning the vocabulary and grammar systems of any major language online. This review of developments in online reading and vocabulary learning summarized surveys of online dictionary use and vocabulary learning strategies use, as well as poster sessions on how to integrate various CALL websites with major learning phases to systematically teach and track vocabulary development online, by using a 'Depth of Lexical Processing Scale' (described in Loucky, 2006). Following recommendations from Grabe's (2004) meta-analys is of research on reading, it demonstrated how teachers can aim to integrate his ten instructional implications for L2 reading with online programs following a clear taxonomy of vocabulary development, to help their learners achieve deeper lexical processing and better retention as a result. These may still be seen online at: http://www.wiziq.com/tutorial/30502Successful-Vocabulary-Learning-Online. This slideshare provides a systematic roadmap to successfulonline second language vocabulary acquisition. That electronic portion of the presentation covered aspects like how to learn new words in any language more effectively, using the Internet and online world to help enhance online $\mathrm{L} 2$ reading development. Grabe's (2004) ten established research-based goals for L2 reading were integrated into a proposed framework for using online reading programs in a way that follows a clear 'Taxonomy of Vocabulary Development (via Deeper Lexical Processing)'.

\section{Future research recommendations:}

Since better understanding of where language education has succeeded in the past is a key to its improvement in the future, important developments in L2 Strategy Research listed by Anderson
(2005: 759) will be summarized As Anderson (1991) defines the process, "strategic reading is not only a matter of knowing what strategy to use, but also the reader must know how to use a strategy successfully and orchestrate its use with other strategies. It is not enough to know about strategies; a reader must als o be able to apply them strategically" [or systematically] (p. 468-469).

Anderson (2005) later also reported that ESL students used a greater number of strategies to support their reading, not surprising because ELLs need more supportive strategies in order to make sense of text that is often foreign to them as EFL or ESL learners. He hypothesized moreover that "metacogni-tive strategies play a more significant role because once a learner understands how to regulate his or her own learning through the use of strategies, language acquisition should proceed at a faster rate" (p. 766).

Showing ESL/EFL learners how to think and communicate about most effective strategies and how to use them is therefore most crucial to help them improve as more advanced, independent language learners who can self-access, self-regulate and monitor their own learning better. Huang, Hsin-chou, Chiou, \& Lin. (2009) reported the same finding that EFL learners, in her case Taiwanese learners, required and used more support strategies, especially depending on their level of computer and language proficiency, background knowledge and text topic and level.

Directions for future strategy research: Appropriate training in the use of most effective language learning strategies has been shown to be most helpful to language learners for the following two reasons, stressed by Anderson. Firstly, "Success ful language learners have a wider repertoire of strategies and [can therefore] draw on a variety of them to 
accomplish their task of learning a language. (2005, p. 757). Secondly, “...metacognitive strategies play a more significant role because once a learner understands how to regulate his or her own learning through the use of strategies, language acquisition should proceed at a faster rate" (2005, p. 766). Finally, three areas still in most need and deserving of more careful research, especially to see how use of CALLTELL or SMALL resources can best help to improve language learning and teaching are probably the same as those noted by Anders on (2005, p. 767) in his review of L2 learning strategies, although in reverse order: 1) the role of computers in L2 strategy research, 2) strategy use in L2 vs. L1 language learning contexts, and 3) how are language learning styles and strategies related?

\footnotetext{
Most Highly Recommended

Vocabulary Learning Programs:

The following vocabulary learning methods and programs have been found to be among the most effective when used by this writer with intermediate and advanced Japanese English learners. Among recommended programs tested, these were deemed most helpful: 1. Semantic Field Keyword Approach (27 Quizzes, Retrieved with Chinese from http://www.call4all.us///misc/sfka.php)

2. http://www.WordChamp.com (best glossing program with 27 free quiz ty pes). 3. V-Check tests from Lexxica.com for free level estimates.

4. Vocabulary Assessment Forms-Authordesigned for free classroom use, accessible http://www.call4all.us///home/_all.php?fi=../m isc/forms). V-Page). ***On-line DAVIE VKS Form, VLS Taxonomy and Depth Scale.

5. Multi-level online reading labs and vocabulary programs listed on V-Page, such as programs recommended to enhance each lexical processing phase.

7. Integrated Multi-level programs like ESL Gold.net and others like it.
}

8. Data-Driven Learning, (DDL) or corpus-based language learning using authentic texts.

9. CALL Efficacy Model—Qing \& Kelly (2009) provide best model of CAVL so far. Qing (2009) most thorough on SLVA also!

\section{References}

Anderson, N. J. (1991). Individual differences in strategy use in second language reading and testing. Modern Language Journal, 75, 460472.

Anderson, N. J. (2005). L2 strategy research. In E. Hinkel (Eds.), Handbook of research in second language teaching and learning (pp. 757-772). Mahway, N.J.: Lawrence Erlbaum Associates. Retrieved from http://dafl.ntpu.edu.tw/files/news/56 0bf0e1bf.pdf

Anderson, N.J. (2003). Metacognition in writing: Facilitating writer awareness. In A. Stubbs \& J. Chapman (Eds.), Rhetoric, uncertainty, and the university as text: How students construct the academic experience (pp. 10-30). Canadian Plains Research Center, University of Regina: Regina, Canada.

Chapelle, C. A., \& Jamieson, J. (2008) Tips for Teaching with CALL: Practical approaches to computer-assisted language learning, (Ed.) H. Douglas Brown. Pearson Education: N.Y.

Cohen, A. \& Macaro, E. (2007). Language Learner Strategies: 30 Years of Research and Practice. OUP Oxford. [Retrieved from ]. Grabe, W. (2004). Research on teaching reading. Annual Review of Applied Linguistics, 24, 44-69.

Gu, Y., \& Johnson, R. K. (1996).Vocabulary learning strategies and language learning outcomes. Language Learning, 46, (4) 643679.

Hirschel, R. (2012). Moodle: Students perspectives on forums, glossaries and quizzes. JALT CALL Journal, Vol. 8, No. 2. p.97, Table 1. [Retrieved from http://journal.jaltcall.org/articles/8 2 Hirschel.pdf].

Huang, Hsin-chou, Chiou-lan Chern, Chihcheng, Lin. (2009). EFL learners' use of online reading strategies and comprehension of texts: An exploratory study Source. 
Computers \& Education, Volume 52 , Issue 1. [http://portal.acm.org/citation.cfm?id=146453 1.1465358]

Jamieson, J. \& Chapelle, C. A. (2004). Issues in CALL Evaluation. CALL 2004 Proceedings: CALL and Research Methodologies. University of Antwerp, Belgium. 179-189.

Jin, L., \& Deifell, E. (Forthcoming). Foreign Language Learners' Use and Perception of Online Dictionaries: A Survey Study" (\#2203), which was submitted to the MERLOT Journal of Online Learning and Teaching. SLOAN: JOLT.

Loucky, J. P. (1996). Developing and testing vocabulary training methods and materials for Jap anese college students study ing English as a foreign language. Ed. D. Dissertation with Pensacola Christian College, Pensacola, FL.

Loucky, J. P. (2004). Improving cognitive, linguistic and computational processing of new vocabulary using an online Semantic Field Key word Approach. Jap an Association of Language Teachers CALL Special Interest Group, C@lling Japan. Spring 2004, Vol. 12/1, pp. 7-20.

Loucky, J. P. (2005a). When Eastern and Western Language Systems Meet: Crossing the English Vocabulary Threshold Versus Breaking the Kanji Barrier GEMA Online Journal of Language Studies, Vol. 5 (2), 2005. [Retrieved from http://www.ukm.my/ppbl/Gema/gemaarchives .html\#volume52].

Loucky, J. P. (2005b). Combining beneficial strategies from both intensive and extensive reading approaches for more effective and enjoy able language learning. JALT 2004 Language Learning for Life: JALT 2004 Conference Proceedings. Pp.1-15. [Retrieved from $\mathrm{http://jalt-}$ publications.org/archive/proceedings/2004/E08.pdf]. Loucky, J. P. (2006). Maximizing vocabulary development by systematically using a depth of lexical processing taxonomy, CALL resources, and effective strategies. CALICO Journal, 23, No. 2 (January), 363-399. [Retreived from https://calico.org/html/article 124.pdf].
Loucky, J. P. (2010). Comparing electronic dictionary functions and use. CALICO Journal, 28(1), 156-174. [Retrieved from http://journals.sfu.ca/CALICO/index. php/calico/article/view/885].

Loucky, J. P., \& Tuzi, F. L. (2010). Comparing foreign language learners' use of online glossing programs. IJVPLE 1(4). IGI Global. Retrieved from: igiglobal.com/Bookstore/TitleDetails. aspx?TitleId=11 $\underline{34}$.

Nation, I. S. P. (2001). Learning vocabulary in another language. Cambridge: Cambridge University Press.

Nunan, D. (1991) Does learner strategy training make a difference? Lenguas Modernas, 24, 123-142.

Oxford, R. (1990). Language learning strategies: What every teacher should know. N.Y.: Newbury House.

Qing Ma, \& Kelly P. (2006). CALL, Vol. 19, No 1, 15-45.

Qing Ma. (2009). Bern: Peter Lang. Second Language Vocabulary Acquisition.

Rose, H. (2012). Language learning strategy research: Where do we go from here? Studies in Self-Access Learning Journal, 3(2), 137148.「sisaljournal.org/archives/jun12/rose/」 Schmitt, N. (1997). Vocabulary learning strategies. In Schmitt, N., \& McCarthy, M. (Eds.), Vocabulary: Description, acquisition and pedagogy. Cambridge: Cambridge University Press.

Shield, L., \& Kukulska-Hume, A. (2004). Language learning web sites: Designing for usability. TEL \& CAL: Zeitschrift fur Neue Lernkulturen. (1. Quartal, Janner 2004), pp. 27-32.

Stevens, V. (2009). Celebrating 25 years of CALL. [Retrieved from http://www.slideshare.net/vances/celebrating25-years-of-call 
